\title{
Estudio de la excreción y transmisión del aislado chileno del virus del síndrome respiratorio y reproductivo porcino (PRRS) en animales inoculados experimentalmente y centinelas en contacto mediante RT-nPCR y ELISA ${ }^{\#}$
}

\author{
Excretion and transmission study of the Chilean porcine reproductive and respiratory syndrome \\ virus isolate by means of RT-nPCR and ELISA in experimentally inoculated animals and sentinels \\ in contact
}

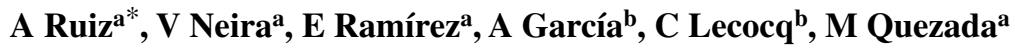 \\ ${ }^{a}$ Facultad de Medicina Veterinaria, Universidad de Concepción, Chillán, Chile. \\ ${ }^{\mathrm{b}}$ Departamento de Laboratorios y Estaciones Cuarentenarias Agrícolas y Pecuarias, \\ Complejo Lo Aguirre, Servicio Agrícola y Ganadero, Santiago, Chile.
}

\begin{abstract}
SUMMARY
The excretion and transmission of PRRSV was studied through RT-nPCR in nasal secretion and serum samples, together with detection of antibodies by ELISA. Thirty pigs, of 3 weeks age, were used and they were randomly assigned into 6 groups. One group of pigs (G1) was inoculated intranasally with $2 \mathrm{ml}$ and intramuscularly with $1 \mathrm{ml}$ with the 2402 isolate in a concentration of $10^{5.7}$ TCID50 per ml, and they were kept for 35 days in an isolation unit. Four groups (G2, G3, G4, G5) were used as susceptible and they were in contact with the inoculated pigs (G1). Group 1 showed that the Chilean PRRSV isolated induces a condition of viremia beginning at 3 days post infection (dpi), increasing at $7 \mathrm{dpi}$, and then declines until $35 \mathrm{dpi}(\mathrm{P}<0.1)$. The virus was detected in the nasal swabs, from $3 \mathrm{dpi}$, increasing at $7 \mathrm{dpi}$, and remaining like that until $19 \mathrm{dpi}$. On the other hand, G2 had a $60 \%$ of viremic animals at 5 days post contact (dpc) and then $100 \%$ at $12 \mathrm{dpc}$; G3 showed a $80 \%$ of positive pigs at $5 \mathrm{dpc}$ and $100 \%$ at $12 \mathrm{dpc}$; G4 had $100 \%$ of viremic pigs at 5 and $12 \mathrm{dpc}$; and finally, G5 showed only a $60 \%$ of positive animals at $12 \mathrm{dpc}$. The results suggest that the national isolate induces an early viremia and is excreted through nasal secretions; moreover, it induces sero-reaction in presence of viremia. It can be concluded that the national isolate of PRRSV was transmitted from G1 to the contact groups between 3 and $28 \mathrm{dpi}$, being this transmission more effective between 3 and 21 dpi.
\end{abstract}

Palabras clave: PRRS, PRRSV, transmisión, excreción.

Key words: PRRS, PRRSV, transmission, excretion.

\section{INTRODUCCIÓN}

El síndrome respiratorio y reproductivo porcino (PRRS) se describió por primera vez en la década de los 80 y actualmente es una de las enfermedades de mayor importancia económica en la industria porcina a nivel mundial (Wills y col 2002). Las pérdidas causadas por esta enfermedad se estiman hasta US\$ 302 por hembra/año y se deben, principalmente, al aumento de la tasa de mortalidad perinatal, disminución de la tasa de crecimiento y aumento de los costos por concepto de vacunación y medicación (Done y Paton 1995, Holck y Polson 2003). La enfermedad típica de esta infección se caracteriza por el aborto tardío en cerdas y chanchillas, y neumonía intersticial en cerdos de recría que se complica por cuadros bacterianos o virales secundarios. Por otro lado, este virus tiene la particularidad de producir infecciones persistentes (Lager y Mengeling 1995, Rossow 1998).

Aceptado: 22.04.2009.

\# Financiado por el Proyecto FONDECYT 1040414.

* Casilla 537, Chillán, Chile; aruiz@udec.cl
La enfermedad se transmite generalmente cuando hay un estrecho contacto entre los cerdos (Yoon y col 1993, Wills y col 1997), en donde el virus ingresa al animal principalmente por vía nasal, aunque se describen otras vías de transmisión como la vía oral, intramuscular, intraperitoneal, transplacentaria y vaginal (Dee y Molitor 1998). El virus es eliminado por los animales infectados a través de sus secreciones y excreciones; es así como PRRSV es eliminado por la saliva hasta 42 días postinfección (dpi), orina hasta $14 \mathrm{dpi}$, heces hasta 35 dpi, secreciones nasales hasta 21 dpi (Yoon y col 1993, Rossow y col 1994, Wills y col 1997). Además, se ha demostrado la transmisión del virus a través del semen de verracos infectados (Gradil y col 1996, Reicks y col 2006). También es importante la transmisión del virus a través de fomites (Otake y col 2002a), habiéndose demostrado la transmisión por agujas de inyección contaminadas (Otake y col 2002 ), manos, botas y ropa de trabajo del personal que está en contacto con cerdos infectados (Otake y col 2002 $2^{\mathrm{a}}$ ). Para minimizar el riesgo de transmisión por estas causas se pueden implementar estrictos protocolos de bioseguridad, los cuales tienen buenos resultados $($ Otake y col 2002 $)$. En los últimos 
años se ha evidenciado la transmisión mecánica del virus a través de mosquitos (Aedes vexans) (Otake y col 2002 ${ }^{\mathrm{c}}$, Otake y col $2003^{\mathrm{b}}$ ) y mosca común (Musca domestica Linneaus), pudiendo sobrevivir en sus vísceras, como en el exterior del insecto (Otake y col 2003 ${ }^{\mathrm{a}}$ ).

El virus ingresa primariamente al organismo por vía aerógena, multiplicándose en macrófagos del cornete nasal, tonsilas y/o pulmón (Rossow 1998); posteriormente, el virus llega por vía linfática a los nódulos linfáticos regionales, alcanzando más tarde la circulación sanguínea y así se distribuye en todos los tejidos, en donde el virus se multiplica masivamente en macrófagos de todo el organismo (Rossow y col 1995, Benfield y col 1999). Al distribuirse por el organismo el virus puede causar una serie de lesiones, como neumonía intersticial, encefalitis, miocarditis y artritis, provocando consecuentemente la enfermedad clínica, cuadro que depende principalmente de la edad del paciente y de la cepa viral (Rossow y col 1995).

Entre los años 1999 y 2000 en monitoreos realizados por el SAG en nuestro país se encontró por primera vez seropositividad del virus PRRS. De un total de 2.328 muestras, un $11,6 \%$ fueron positivas (277 muestras) (Ruiz y col 2003). En el año 2001 se realizó un muestreo serológico a 6.179 cerdos pertenecientes a 150 unidades productivas a lo largo de todo el país, observándose 22 planteles con serología correspondiente a PRRSV (Ruiz y col 2003).

Hasta el momento, en nuestro país se ha detectado solo un aislado viral, que corresponde a un genotipo norteamericano. En Chile no existen antecedentes bibliográficos acerca del comportamiento epidemiológico del aislado presente, ni evaluaciones económicas del daño que ha causado a la producción nacional. Es necesario aislar, tipificar e investigar la patogenicidad de las cepas presentes en Chile pues es sabido que PRRSV puede sufrir mutaciones, por lo que se puede esperar que el virus presente en nuestro país haya sufrido ciertos cambios (Ruiz y col 2003). Se cree que el aislado nacional de PRRSV es de menor patogenicidad que los aislados norteamericanos (cepa ATCC VR-2332), causantes de graves cuadros respiratorios y reproductivos en Estados Unidos y Canadá, por lo tanto, en Chile la enfermedad se comportaría epidemiológicamente distinta, con una diseminación más lenta en el organismo y una excreción más tardía, infectando a los cerdos susceptibles en mayores períodos de tiempo (Ruiz y col 2003).

El objetivo del presente trabajo fue estudiar el patrón de comportamiento y transmisión de la enfermedad a grupos de cerdos susceptibles expuestos por contacto directo.

El estudio propuesto permitirá tener un modelo más preciso acerca de los períodos de excreción del virus, así como el momento en que los cerdos susceptibles puedan infectarse.

\section{MATERIAL Y MÉTODOS}

\section{CULTIVOS CELULARES Y AISLAMIENTO VIRAL}

El aislado nacional del virus PRRS corresponde a un genotipo norteamericano (cepa 2402), siendo el único aislado que oficialmente se ha identificado en Chile, el cual fue titulado y genotipificado por el Dr. Fernando Osorio en el Centro de Diagnóstico Veterinario del Departamento de Veterinaria y Ciencias Biomédicas de la Universidad de Nebraska-Lincoln, quien proporcionó el aislado nacional para el presente estudio, mantenido en cultivos celulares (MARC 145).

\section{DISEÑO DEL EXPERIMENTO}

Se realizó una experiencia con 30 cerdos híbridos de ambos sexos, de tres semanas de edad, provenientes de una pirámide genética de alta salud y libre de PRRS, los cuales se dividieron al azar en 6 grupos ( 5 animales cada grupo), de los cuales un grupo (G1) fue inoculado con 2 $\mathrm{ml}$ por vía intranasal y $1 \mathrm{ml}$ por vía intramuscular (basado en experimentos realizados anteriormente) con un inóculo del aislado 2402 de virus PRRS en concentración de $10^{5.7}$ TCID50 por ml mantenido en células MARC-145. Es importante destacar que el virus solo tenía un pasaje celular previo al inóculo. Otros 4 grupos de cerdos (grupo G2, G3, G4 y G5) se utilizaron como susceptibles y entraron en contacto directo con los cerdos inoculados, en el mismo corral, entre los 3 y 7 dpi, 10 y 14 dpi, 17 y 21 dpi y 24 y 28 dpi, respectivamente, permitiendo un estrecho contacto nariz con nariz. Posterior al contacto, estos grupos fueron mantenidos en diferentes unidades de aislamiento independientes. El último grupo (G6) corresponde al grupo control, siendo inoculado con un cultivo celular puro.

Antes de comenzar la experiencia se realizó un período de aclimatación de una semana de los cerdos, en el que se obtuvieron muestras de sangre individuales, para constatar su condición de negativos a PRRSV a través de análisis serológicos (ELISA) y moleculares (RT-nPCR). También se realizaron exámenes microbiológicos para descartar enfermedades sistémicas y respiratorias.

Los grupos 1 y 6 (G1 y G6) se sacrificaron a los 35 días postexposición, mientras que los grupos restantes (G2, G3, G4 y G5) fueron sacrificados a los 12 dpc (días postcontacto) con G1.

La experiencia se realizó en el Departamento de Laboratorios y Estaciones Cuarentenarias Agrícolas y Pecuarias, Complejo Lo Aguirre, perteneciente al SAG, respetando todas las medidas de bioseguridad y de bienestar animal. Los animales fueron mantenidos en tres unidades independientes y atendidos por personal diferente. Cada unidad cuenta con altas medidas de bioseguridad, con temperatura y ventilación controladas. En una de ellas se mantuvo a los cerdos inoculados y a los cerdos en exposición por el período correspondiente; en otra unidad se 
conservaron los cerdos no infectados, y en la última a los cerdos postcontacto con G1.

Cada unidad se desinfectó y fumigó antes del inicio de la experiencia para evitar la presencia de moscas y mosquitos. A su vez, fueron consideradas otras medidas de bioseguridad como, por ejemplo, cambio de botas y uso de pediluvios antes del ingreso a los cuartos, y la utilización de guantes, mascarillas y cofias desechables durante cada ingreso.

\section{TOMA DE MUESTRAS EN CERDOS VIVOS}

Para determinar la infección en los cerdos de G1 se obtuvieron muestras de sangre a los $0,3,7,11,15,19,23$, 27,31 y 35 dpi a través de punción en la vena cava craneal utilizando tubos de vacío (Vacutainer®) de $10 \mathrm{~mL}$ sin anticoagulante, para RT-nPCR y ELISA. Adicionalmente, durante los mismos períodos se tomaron muestras de hisopo nasal para determinar a través de RT-nPCR el momento en el cual los cerdos inoculados excretan el virus. Iguales procedimientos fueron efectuados en los cerdos de G6 durante los mismos períodos de tiempo.

En los animales de los grupos contacto (G2, G3, G4 y G5) se obtuvieron muestras de sangre a los 0, 5 y 12 días postcontacto (dpc) para RT-nPCR y ELISA, utilizando el mismo procedimiento que para G1 y G6.

\section{TÉCNICA DE PCR (RT-nPCR)}

Extracción del material genético: Para la extracción del ARN viral presente en el suero e hisopos nasales se utilizó Trizol ${ }^{\circledR}$ LS Reagent de Invitrogen ${ }^{\mathrm{TM}}$, siguiendo el protocolo recomendado por el fabricante. Luego el material fue conservado a $-20^{\circ} \mathrm{C}$ hasta el siguiente proceso, el cual se realizó a la semana siguiente.

La amplificación del ORF 7 mediante RT-nPCR se realizó en grupos de a 5 muestras, más sus respectivos controles negativo y positivo, este último fue material genético de PRRS extraído desde un cultivo viral puro. Para el desarrollo de la técnica se utilizó el kit comercial QIAGEN One Step RT-PCR, formando una mezcla maestra, la cual contiene: $1 \mathrm{X}$ de buffer PCR, 0,32 mM de dNTPs, 1,25 mM de $\mathrm{MgCl}_{2}, 13 \mathrm{U}$ de RNasa OUT([40 u/ $\left.\mu \mathrm{l}\right]$ Invitrogen ${ }^{\mathrm{TM}}$ ), $0,2 \mu \mathrm{M}$ de cada partidor específico (primer forward ATGGCCAGCCAGTCAATCA y primer reverse CGGATCAGGCGCACAGTATG) (Shin y col 1998), $1 \mu \mathrm{l}$ de QIAGEN One Step RT-PCR enzima Mix, $8 \mu \mathrm{l}$ de templado, completándose a un volumen final de $25 \mu \mathrm{l}$ con agua ultrapura (RNase-free). Posteriormente se procedió a amplificar el segmento ORF 7 del virus PRRS mediante el uso de un termociclador (MJ Research, Peltier Termal Cycler PTC-200). Para amplificar el material genético se realizó primero un proceso de transcripción reversa de $50{ }^{\circ} \mathrm{C}$ durante 30 minutos. A continuación, una desnaturalización inicial a $94{ }^{\circ} \mathrm{C}$ por 15 minutos, posteriormente 40 ciclos que constan de una fase de desnaturalización a $94{ }^{\circ} \mathrm{C}$ por 30 segundos, una fase de apareamiento a $50{ }^{\circ} \mathrm{C}$ por 35 segundos y una fase de elongación a $72{ }^{\circ} \mathrm{C}$ por 35 segundos. Por último, la muestra es sometida a una fase de elongación final a $72{ }^{\circ} \mathrm{C}$ por 7 minutos, obteniéndose un producto de 309 pares de bases (bp), el cual fue utilizado para el PCR anidado (RT-nPCR). Para esto, el producto de RT-PCR fue amplificado mediante partidores internos siguiendo el protocolo estándar de RT-nPCR descrito por Shin y col (1997), que tiene un límite de detección de 120 partículas virales. En forma breve, el protocolo consiste en combinar $1 \mu \mathrm{l}$ de producto de RT-PCR con una muestra maestra constituida por: $0,24 \mathrm{mM}$ de dNTPs, $1 \mathrm{X}$ de buffer PCR, 0,24 $\mu \mathrm{M}$ de cada partidor específico (primer forward CCAGTCAATCAGCTGTGCCA y reverse GCGCCTTGATTAAAGGCGGT) (Shin y col 1998), $2 \mathrm{nM}$ de $\mathrm{MgCl}_{2}, 0,625 \mathrm{U}$ de Taq DNA Polymerase recombinant (Invitrogen ${ }^{\mathrm{TM}}$ ), completándose a un volumen final de $23 \mu$ con agua ultrapura. El proceso de amplificación del material genético se realizó mediante 30 ciclos que constan de un proceso de desnaturalización a $94{ }^{\circ} \mathrm{C}$ por 30 segundos, una fase de apareamiento a $50{ }^{\circ} \mathrm{C}$ por 35 segundos y una fase de elongación a $72{ }^{\circ} \mathrm{C}$ por 35 segundos, obteniendo finalmente un producto de 208 pares de bases (bp), el cual fue conservado a $4{ }^{\circ} \mathrm{C}$ y analizado mediante un gel de agarosa al 1\%, teñido con bromuro de etidio. La imagen es capturada en un transiluminador de rayos UV (M-15, UVP).

\section{ESTUDIO INMUNOENZIMÁTICO (ELISA)}

El suero se utilizó también para la detección de anticuerpos anti-PRRSV mediante la prueba de ELISA, para lo cual se usó un kit comercial (PRRS: Herd Check, IDEXX Laboratories Inc., Westbrook ME, USA), el cual utiliza como antígeno viral un sobrenadante de macrófagos alveolares pulmonares infectados con PRRSV en cultivo celular MARC-145 (Albina y col 1992, Cho y col 1997). En consecuencia, tiene especial preferencia en detectar anticuerpos contra proteínas de membrana (M) y nucleocápside $(\mathrm{N})$, ya que estos son los antígenos más abundantes en el virión (Kwang y col 1999). La técnica considera un valor $\mathrm{S} / \mathrm{P}$ igual 0,4 como punto de corte para considerar una muestra positiva.

\section{ANÁLISIS ESTADÍSTICO}

Los datos fueron analizados estadísticamente por medio del Test de McNemar y la prueba exacta de Fisher; el primero utilizado para evaluar resultados de cada grupo, y el segundo para analizar diferencias entre los grupos.

\section{RESULTADOS}

\section{ANIMALES INOCULADOS}

$R T-n P C R$ de suero. El material genético del virus PRRS no fue detectado a los 0 dpi en el $100 \%$ de los casos. 
Posteriormente, a los 3 dpi el $80 \%$ de los casos resultaron positivos; sin embargo, a los 7, 11 y 15 dpi se observó que un $100 \%$ de los casos fueron positivos a RT-nPCR. En tanto, a los 19 y 23 dpi se detectó el genoma viral en un $80 \%$ de los animales, subsiguientemente a los 27 dpi se obtuvo un $60 \%$ de cerdos positivos. En cambio, a los 31 y 35 dpi solo se observó un $20 \%$ de animales positivos (1 de 5 cerdos) (figura 1).

$R T-n P C R$ de hisopos nasales. Como se muestra en la figura 2 , el $100 \%$ de los animales resultó negativo al inicio de la experiencia. Posteriormente, a los 3 dpi el $60 \%$ de los cerdos fueron positivos y el $20 \%$ de los animales fue clasificado como sospechoso, es decir, se observó una banda tenue, la cual no puede ser considerada como negativa ( 1 de 5 animales). Subsiguientemente, a los 7, 11, 15 y 19 dpi se observó que un $80 \%$ de los casos fueron positivos a RT-nPCR. En tanto, a los 23 y 27 dpi no se detectó el genoma viral en $100 \%$ de los animales. Finalmente, a los 31 y 35 dpi se observó que un $20 \%$ de los animales resultaron sospechosos ( 1 de 5 cerdos).

Análisis serológicos mediante ELISA. No se evidenció serorreacción en los animales entre los 0 dpi y 11 dpi, en tanto a los 15 y 19 dpi el $100 \%$ de los animales resultaron positivos a la prueba; sin embargo, a los 23 dpi solo el $80 \%$ de los cerdos se encuentra positivo (4 de 5 animales). Posteriormente, desde los 27 dpi al sacrificio (35 dpi) se observó serorreacción en el 100\% de los animales.

El grupo control (G6) obtuvo un $100 \%$ de animales negativos al test de ELISA y RT-nPCR de suero e hisopo nasal durante todo el experimento.

\section{GRUPOS CONTACTO (G2 A G5)}

$R T$-nPCR de suero. En ninguno de los grupos contacto fue posible detectar el material genético de PRRSV a los 0 dpc. En el grupo 2 a los 5 dpc se obtuvo un $60 \%$ de animales positivos ( 3 de 5 cerdos), mientras que a los $12 \mathrm{dpc}$ la totalidad de los cerdos resultaron positivos. Por otro lado, en el grupo 3 se observó un $80 \%$ de animales positivos a los $5 \mathrm{dpc}$, en tanto que a los $12 \mathrm{dpc}$ el genoma viral se encontró en la totalidad del grupo. En el cuarto grupo (G4) se obtuvo un $100 \%$ de animales positivos a los 5 y 12 dpc. En su contraparte, el grupo 5 no tuvo positivos a los 5 dpc; sin embargo, a los 12 dpc el genoma viral se detectó en el 60\% de los animales (figura 3).

Análisis serológicos mediante ELISA. Todos los animales de los grupos contacto resultaron seronegativos a los $0 \mathrm{y}$ 5 dpc. No obstante, a los 12 dpc el grupo 2 obtuvo un $60 \%$ de animales positivos ( 3 de 5 cerdos), en el grupo 3 solo el $20 \%$ resultó positivo ( 1 de 5 cerdos) y en el grupo 4 se observó un $40 \%$ de casos seropositivos. Por otro lado, el grupo 5 continuó siendo $100 \%$ seronegativo a los 12 dpc (figura 4).

\section{DISCUSIÓN}

Para lograr el objetivo propuesto, la estrategia se basó en detectar la presencia de material genético de PRRSV en muestras de suero e hisopos nasales, conjuntamente con la presentación de anticuerpos circulantes en cerdos inoculados experimentalmente con el aislado nacional 2402.

\section{GRUPO INOCULADO}

Los resultados demuestran la presencia de genoma viral en la sangre desde los 3 dpi, lo que concuerda con estudios realizados anteriormente por Batista y col $(2002,2004)$ y Trincado y col (2004), en los cuales cerdos inoculados de diferentes edades resultaron positivos al primer muestreo postinoculación, realizado a los 3 dpi mediante el uso de la técnica de PCR. Además, se realizó aislamiento viral sobre las mismas muestras; sin embargo, el virus se obtuvo desde el segundo muestreo postinoculación, realizado a los 7 dpi, demostrando la menor sensibilidad de la segunda técnica. No obstante, otros trabajos han demostrado viremia desde el primer dpi, mediante técnicas moleculares (Spagnuolo-Weaver y col 1998, Gallegos 2005) y de aislamiento viral (Rossow y col 1995), sugiriendo la posibilidad de que PRRSV o su genoma estuviese en la sangre con anterioridad a los 3 dpi.

La presencia de PRRSV en la sangre a los 3 dpi indica que la inoculación viral por vía nasal e intramuscular a la cual fue sometido este grupo de animales resultó ser exitosa. A modo de referencia, un estudio realizado aplicando PCR y ELISA en sangre extraída de cerdos, de 4 semanas de edad, demostró que no existe diferencia estadística al comparar ambas rutas de infección, siendo más importante la dosis infectante (Yoon y col 1999). El incremento de cerdos positivos a los 7 dpi se podría explicar por el hecho de que un animal comenzó su viremia tardíamente, resultando negativo a RT-nPCR a los 3 dpi, lo cual se debería a diferencias biológicas individuales, lo que concuerda con estudios realizados por Yoon y col (1995) y Batista y col (2002) en donde se observó un aumento de casos positivos posterior a los $3 \mathrm{dpi}$. La meseta observada entre 7 y $15 \mathrm{dpi}$, en donde todos los animales son positivos, concuerda con estudios anteriormente realizados (Batista y col 2002, Wills y col 2003, Trincado y col 2004) en los cuales existe un plateau entre estos días. Posteriormente, desde los 19 dpi en adelante, la viremia tiende a desaparecer paulatinamente hasta el último muestreo, realizado a los 35 dpi, en donde sólo existe un cerdo positivo, concordando con estudios realizados con anterioridad (Rossow y col 1994, Spagnuolo-Weaver y col 1998, Wills y col 2003); esta disminución estaría directamente influenciada por la aparición de anticuerpos neutralizantes, la que se iniciaría entre los 15 a 21 dpi, según lo descrito por Yoon y col (1995), Bautista y Molitor (1997), Molitor y col (1997), Osorio y col (2002) y Batista y col (2004), quienes desarrollaron estudios de seroneutralización viral en animales inoculados 


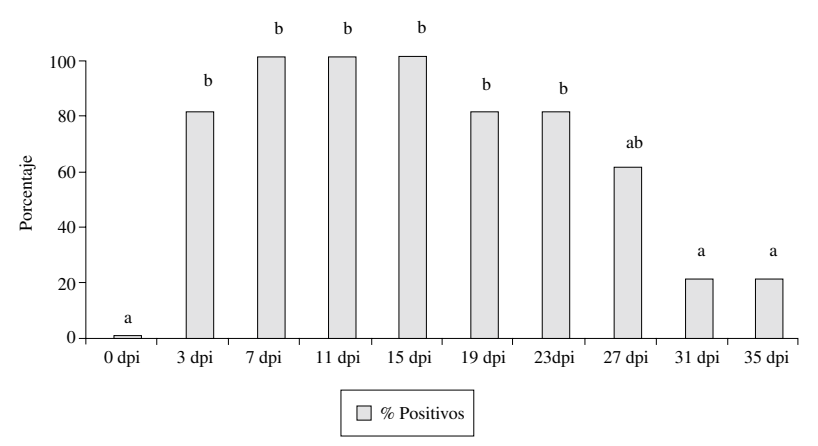

Figura 1. Resultados de RT-nPCR en suero, expresados en porcentaje de cerdos positivos, del grupo de animales inoculados experimentalmente con aislado 2402 de PRRSV. Las letras distintas sobre las barras indican diferencias estadísticamente significativas.

dpi: días postinoculación.

RT-nPCR results of serum, expressed as a percentage of positive pigs from experimentally inoculated animals with PRRS virus strain 2402. Different letters above the bars indicate statistically significant differences.

dpi: days post infection.

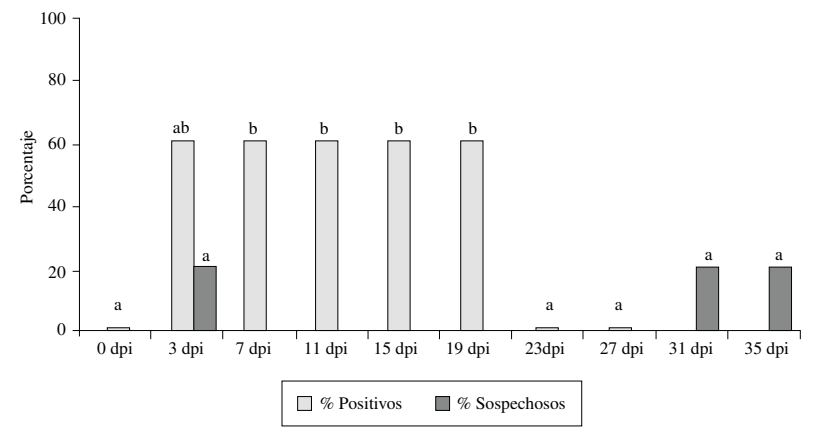

Figura 2. Resultados de RT-nPCR de hisopos nasales, expresados en porcentaje de cerdos positivos, del grupo de animales inoculados experimentalmente con aislado 2402 de PRRSV. Las letras distintas sobre las barras indican diferencias estadísticamente significativas.

dpi: días post inoculación.

RT-nPCR results of nasal swabs, expressed as a percentage of positive pigs from experimentally inoculated animals with PRRS virus strain 2402. Different letters above the bars indicate statistically significant differences.

dpi: days post infection.

con PRRSV. Del mismo modo, Bautista y Molitor (1997), Molitor y col (1997), Batista y col (2004) han señalado la importancia de la respuesta inmune mediada por la proliferación de linfocitos T a partir de los 21 dpi, conjuntamente con el aumento de INF- $\gamma$ producido por células a partir de los 14 dpi, el cual fue descrito por Batista y col (2004), a través de citometría de flujo. Sin embargo, lo anterior no puede ser afirmado, ya que en el presente estudio no se realizó detección de anticuerpos neutralizantes, niveles de linfocitos T, ni producción de INF- $\gamma$.

Por otro lado, los resultados demuestran la presencia de material genético en secreción nasal entre los 3 y 19

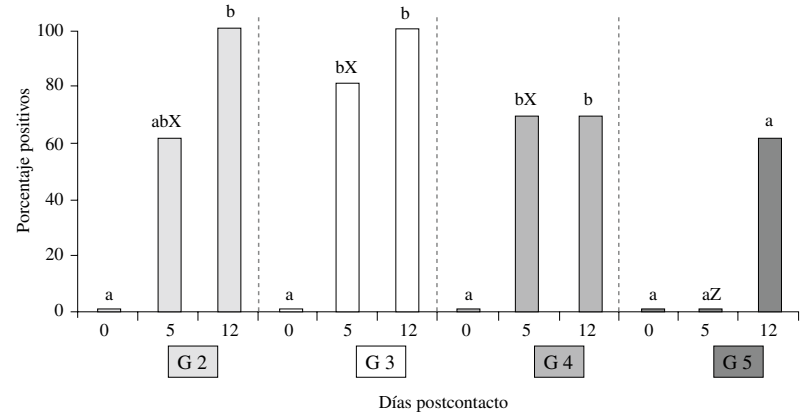

Figura 3. Resultados de RT-nPCR en suero, expresados en porcentaje de cerdos positivos, de los grupos de animales contacto. Las letras distintas sobre las barras ( $\mathrm{a}$ y b) indican diferencias estadísticamente significativas dentro de cada uno de los grupos. Las distintas letras mayúsculas sobre las barras (X y Z) indican diferencias estadísticamente significativas entre los grupos. G2: Grupo 2, G3: Grupo 3, G4: Grupo 4, G5: Grupo 5.

Serum RT-nPCR results, expressed as a percentage of positive pigs from the contact animals groups. Different letters above the bars ( $a$ and $b)$ show statistically significant differences within each group. Different capital letters above the bars (X and Z) show statistically significant differences between groups.

G2: Group 2, G3: Group 3, G4: Group 4, G5: Group 5.

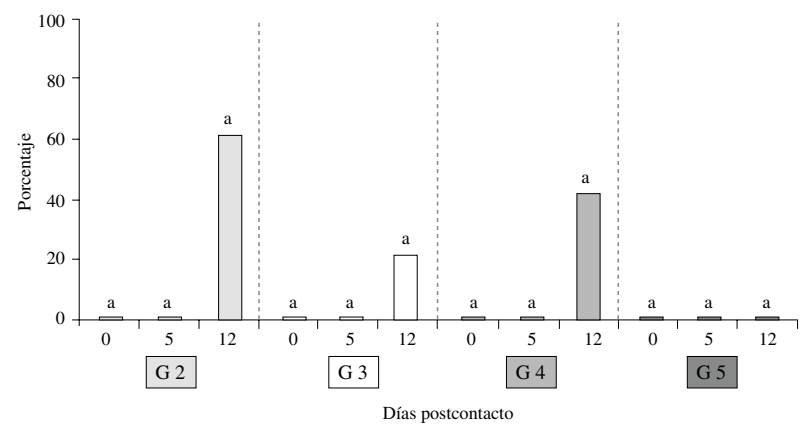

Figura 4. Resultados de ELISA, expresados en porcentaje de cerdos positivos, de los grupos de animales contacto. Las letras distintas sobre las barras indican diferencias estadísticamente significativas dentro de cada uno de los grupos.

G2: Grupo 2, G3: Grupo 3, G4: Grupo 4, G5: Grupo 5

ELISA results, expressed as a percentage of positive pigs from the contact animals groups. Different letters above the bars indicate statistically significant differences within each group.

G2: Group 2, G3: Group 3, G4: Group 4, G5: Group 5.

dpi, señalando excreción viral por esta vía, lo que ya ha sido confirmado anteriormente mediante estudios de aislamiento viral realizados por Yoon y col (1993), Rossow y col (1994), Rossow y col (1995), quienes indican que esta secreción es una ruta de eliminación de partículas virales infectantes. Sin embargo, los datos obtenidos muestran la presencia constante de genoma viral en los hisopos, contrario a lo observado por los autores anteriormente señalados, lo que se explicaría por la mayor sensibilidad de la técnica de RT-nPCR usada en el presente experimento. Estos resultados concuerdan con estudios realizados por Gallegos (2005), quien mediante RT-nPCR obtuvo un patrón 
similar de excreción viral en animales inoculados con la cepa 2402 de PRRSV. No obstante, las muestras positivas podrían corresponder a restos del inóculo administrado, a partículas virales excretadas desde el animal o a una combinación de ambas, pudiendo ser algunas muestras positivas producto de restos del inóculo que se encuentra aún en la zona nasal y otras debido a la replicación viral; desafortunadamente esto no se puede corroborar, ya que el RT-nPCR no diferencia entre virus completo o parte de su genoma, lo que sí puede ser demostrado a través de cultivo viral o en este caso mediante el uso de centinelas, los cuales se introdujeron al corral de G1 desde los 3 dpi.

La disminución de cerdos positivos observada posterior a los 19 dpi puede corresponder a un comportamiento cíclico de excreción viral, lo que ha sido observado en estudios de aislamiento viral realizados por Yoon y col (1993) en cerdos de cinco meses de edad; sin embargo, en este caso no fue posible observar este fenómeno, al igual que en los estudios realizados por Sandoval (2004) y Gallegos (2005) en condiciones similares, posiblemente por diferencias de la cepa viral infectante, la madurez de los individuos y método de diagnóstico. Por otro lado, estudios de aislamiento viral realizados por Rossow y col (1995) demostraron altos títulos de PRRSV en epitelio de cornete nasal hasta los $21 \mathrm{dpi} \mathrm{y,} \mathrm{al}$ mismo tiempo, trataron de aislar el virus desde secreciones nasales pero no tuvieron éxito debido posiblemente a errores de muestreo, según lo señalado por el autor. Sin embargo, señalan la posibilidad de transmisión de la enfermedad por esta vía debido a la eventual eliminación de partículas virales a través del epitelio del cornete nasal, concordando con los resultados del presente estudio.

En cuanto al ELISA, se evidenció serorreacción (relación $\mathrm{s} / \mathrm{p} \geq 0,4)$ a PRRSV desde los 15 dpi, lo que correspondería a un aumento de anticuerpos contra las proteínas $\mathrm{M}$ y $\mathrm{N}$ del virión (Kwang y col 1999). Esta respuesta serológica se asemeja a resultados obtenidos en estudios anteriormente realizados por Bierk y col (2001), Batista y col (2002), Wills y col (2003) y Trincado y col (2004) en cerdos de diferentes edades, de 1 a 5 meses, inoculados con PRRSV, indicando serorreacción, a través a ELISA, desde los $14 \mathrm{dpi}$, la cual no es protectiva y solo es de importancia diagnóstica. Por otro lado, existen estudios serológicos de PRRSV mediante otros métodos, por ejemplo, mediante la utilización de IFA. Rossow y col (1994) demostraron la presencia de anticuerpos circulantes desde los $7 \mathrm{dpi}$, a su vez, Yoon y col (1995) mediante IMPA detectaron sueros positivos desde los $5 \mathrm{dpi}$, lo cual indica una mejor sensibilidad en estas técnicas diagnósticas comparada con ELISA. El menor porcentaje de cerdos positivos a los 23 dpi no concuerda con estudios realizados por Yoon y col (1999), Bierk y col (2001), Batista y col (2002), Wills y col (2003), López y Osorio (2004) en cerdos de distintas edades y diferentes cepas de PRRSV en los cuales todos los animales inoculados se mantienen positivos a ELISA por sobre los $60 \mathrm{dpi}$, aunque los valores s/p de estos decaen posterior a los 28 dpi se mantuvieron siempre sobre 0,4 . Por lo anteriormente mencionado, y al haber repetido el
ELISA de esta muestra obteniendo el mismo resultado, es probable que sea un caso de falso negativo, y la técnica no haya podido detectar niveles bajos de anticuerpos en ese momento, como antecedente, es importante destacar que este ELISA tiene 95\% de sensibilidad (Albina y col 1994, Polson y col 2003). Pese a lo señalado anteriormente, este cambio no es de significancia estadística.

\section{GRUPOS CONTACTO (G2 A G5)}

Como ha sido anteriormente señalado, todos estos cerdos estuvieron en contacto con los animales de G1, los cuales se infectaron y excretaron PRRSV de la manera esperada. La distribución temporal fue: G2 estuvo en contacto con G1 entre el $3^{\text {er }}$ y $7^{\mathrm{mo}}$ dpi, G3 entre el $10^{\mathrm{mo}}$ y $14^{\text {vo }}$ dpi, G4 entre el $17^{\mathrm{mo}}$ y $21^{\mathrm{er}}$ dpi y el grupo 5 (G5) desde el $24^{\text {to }}$ al $28^{\text {vo }}$ dpi.

Los resultados indican la existencia de dos patrones de comportamiento en los animales. El primero está constituido por $\mathrm{G} 2$, G3 y G4, los que tienen por característica presentar a lo menos el $60 \%$ de animales positivos a los 5 dpc y el $100 \%$ a los 12 dpc, indicando una transmisión temprana de PRRSV. Por otro lado, el grupo 5 solo presentó animales positivos a los $12 \mathrm{dpc}$, demostrando que en estos animales pudo ocurrir una transmisión tardía, que probablemente ocurrió durante el último día que tuvieron contacto con G1, lo que explicaría la ausencia de animales positivos a los $5 \mathrm{dpc}$. Otra opción sería una infección con menor carga viral, ya que en el momento que G5 estuvo en contacto con G1 había disminuido el porcentaje de animales virémicos en dicho grupo, adicionalmente, los resultados RT-nPCR de hisopos nasales eran negativos. Este último punto concuerda con estudios realizados por Yoon y col (1999), en donde señalan que una menor dosis infectante produce una viremia más tardía. De cualquier forma, en ambos patrones el virus debió ingresar al organismo por el estrecho contacto entre los animales, en donde PRRSV entró vía oronasal, multiplicándose en macrófagos del cornete nasal, tonsilas y/o pulmón, para posteriormente por vía linfática llegar a los nódulos linfáticos, alcanzando más tarde la circulación sanguínea a las 12 horas postinoculación según lo descrito anteriormente por Rossow y col (1995) y Benfield y col (1999).

Los resultados serológicos nuevamente muestran la existencia de dos patrones de comportamiento en los animales; el primero está constituido por G2, G3 y G4, que se caracterizan por tener serorreacción a PRRSV, sugiriendo la infección temprana de algunos animales dentro de cada grupo, los que desarrollaron una respuesta humoral, la que fue evidenciada mediante ELISA; además, hace pensar que los animales seronegativos se infectaron más tardíamente, por tanto sus organismos aún no desarrollaban anticuerpos al momento del último muestreo. Por otro lado, el que G5 no tenga animales positivos a ELISA insinúa una tardía transmisión del virus, siendo confirmado por los resultados de RT-nPCR, que indican 
probablemente una menor transmisión entre los días en que fue expuesto este grupo de animales.

\section{RELACIÓN ENTRE GRUPO 1 Y GRUPOS CONTACTO}

Los datos obtenidos sugieren que los animales inoculados se infectaron y eliminaron virus a través de secreciones nasales, desde los 3 dpi y hasta los 19 dpi, momento en que serían capaces de transmitir la enfermedad a través de esta vía de excreción, lo que se confirma en el presente estudio ya que los animales de los grupos contacto efectivamente se infectaron siendo esto demostrado mediante RT-nPCR y ELISA. Así, un conjunto de animales susceptibles se infectó tempranamente con PRRSV, estos fueron los grupos 2, 3 y 4 expuestos a $\mathrm{G} 1$ entre los 3 y 21 dpi, no existiendo diferencia estadísticamente significativa entre sus niveles de infección. En contraparte, G5, presumiblemente con una menor y mas tardía infección, el cual fue expuesto a G1 desde los 24 dpi, evidencia una menor capacidad de transmisión del virus por parte de los animales inoculados, concordando con estudios previamente realizados por Yoon y col (1993) quienes demostraron que animales inoculados son capaces de transmitir PRRSV entre los 3 y 35 dpi; sin embargo, la transmisión disminuye considerablemente después de los 25 dpi. Por otro lado, Wills y col (2002) evidenciaron transmisión viral hasta los 62 dpi, aunque con una notable baja en el nivel de propagación del virión entre los 27 y 41 dpi. Es probable que en el presente estudio PRRSV se transmitiera a través de secreciones nasales hasta los 19 dpi y posteriormente existiera un cambio de ruta de transmisión, siendo esta de menor efectividad, como puede ser la transmisión por heces o saliva; sin embargo, no es posible confirmar si hubo otras fuentes de excreción del virus pues no fueron estudiadas en este experimento. Por otro lado, otra explicación lógica es que a medida que pasan los días la intensidad de excreta sea menor y, es posible incluso, que sea inconstante, lo que reduce la probabilidad de contacto efectivo por unidad de tiempo y, por lo tanto, menor proporción de infección.

Los resultados de ELISA despiertan algunas inquietudes, ya que animales de grupos contacto son positivos desde los 12 dpc; sin embargo, en G1 se demuestra seroreacción posterior a los $15 \mathrm{dpi}$, lo que puede ser explicado por medio de las siguientes hipótesis: Los animales de G1 fueron positivos desde los $12 \mathrm{dpi}$, al igual que los animales positivos de los grupos contacto, pero esto no pudo ser evidenciado, ya que no hubo muestreos en esa fecha y solo se evidenció a los 15 dpi. La otra opción es que haya existido diferente respuesta serológica entre el grupo inoculado y los contactos, lo cual se podría deber a una reactivación del virus en los cerdos inoculados.

En conclusión, los resultados obtenidos en el presente estudio indican que en cerdos inoculados con el aislado nacional el genoma de PRRSV se puede detectar a través de RT-nPCR en muestras de suero entre los 3 y 35 dpi, siendo detectado de mejor forma entre los 3 y 15 dpi.
Asimismo, se puede detectar en muestras de hisopo nasal entre los 3 y 19 dpi, observándose también serorreacción entre los 12 y 15 dpi.

El aislado nacional de PRRSV puede ser transmitido por animales inoculados a cerdos contacto entre los $3 \mathrm{y}$ 28 dpi, siendo más efectiva entre los 3 y 21 dpi.

\section{RESUMEN}

La excreción y transmisión de PRRSV fue estudiada a través de RT-nPCR en muestras de secreción nasal y suero, junto con la detección de anticuerpos por medio de ELISA. Se utilizaron 30 cerdos de 3 semanas de edad, los cuales fueron divididos en 6 grupos al azar. Los cerdos de un grupo (G1) fueron inoculados con $2 \mathrm{ml}$ por vía intranasal y $1 \mathrm{ml}$ por vía intramuscular de un inóculo del aislado 2402 en concentración de $10^{5,7}$ TCID50 por $\mathrm{ml}$, y fueron mantenidos por 35 días en una unidad de aislamiento, período en el cual fueron muestreados para RT-nPCR y ELISA a los $0,3,7,11,15,19,23,27,31$ y 35 días postinoculación (dpi). Cuatro grupos (G2, G3, G4, G5) se utilizaron como susceptibles, y estuvieron en contacto con los cerdos inoculados entre los 3 y 7 dpi, 10 y 14 dpi, 17 y 21 dpi y 24 y 28 dpi, respectivamente, siendo mantenidos en unidades de aislamiento independiente posterior al contacto, obteniéndose muestras de sangre para RT-nPCR y ELISA a los 0, 5 y 12 días postcontacto (dpc). El sexto grupo correspondió al grupo control (G6) que siguió el mismo protocolo que G1. En los cerdos del grupo 1 los resultados indican que el aislado nacional de PRRSV induce un estado de viremia a partir de los 3 dpi (80\%), la cual aumenta a los 7 dpi (100\%), para comenzar a decaer hasta los 35 dpi $(20 \%)(\mathrm{P}<0,1)$. En los hisopos nasales se detectó el virus a través de RT-nPCR desde los 3 dpi (60\%), aumentando a los 7 dpi $(80 \%)$, manteniéndose así hasta los 19 dpi. Por otra parte, G2 obtuvo un $60 \%$ de animales virémicos desde los 5 dpc y luego $100 \%$ a los 12 dpc; G3, un $80 \%$ de cerdos positivos a los 5 y $100 \%$ a los 12 dpc; G4 un $100 \%$ de cerdos virémicos a los 5 y 12 dpc; finalmente G5 con solo un $60 \%$ de animales positivos a los $12 \mathrm{dpc}$. Los resultados sugieren que el aislado nacional induce una viremia temprana y es excretado a través de secreciones nasales, además, induce serorreacción en presencia de viremia. Se concluye que el aislado nacional de PRRSV se transmitió desde G1 a cerdos de grupos contacto entre los 3 y 28 dpi, siendo esta transmisión más efectiva entre los 3 y 21 dpi.

\section{AGRADECIMIENTOS}

Este trabajo fue financiado por el proyecto FONDECYT (CHILE) $\mathrm{N}^{\circ}$ 1040414. Los autores desean agradecer a las autoridades del Servicio Agrícola y Ganadero por el apoyo al proyecto y al Dr. Fernando Osorio de la Universidad de Nebraska, Lincoln, USA, por el asesoramiento virológico.

\section{REFERENCIAS}

Albina E, Y Leforban, T Baron, JP Duran, P Vannier. 1992. An enzyme linked immunosorbent assay (ELISA) for the detection of antibodies to porcine reproductive and respiratory syndrome (PRRS) virus. Ann Rech Vet 23, 167-176.

Albina EF, R Madec, J Cariolet J Torsión. 1994. Immune response and persistence of porcine reproductive and respiratory syndrome virus in infected pigs and farm units. Vet Rec 134, 567-573.

Batista L, S Dee, K Rossow, J Deen, C Pijoan. 2002. Assessing the duration of porcine reproductive and respiratory syndrome virus persistence and shedding in a large population of breeding age female swine. Can J Vet Res 66,196-200.

Batista L, C Pijoan, S Dee. 2004. Virological and immunological responses to porcine reproductive and respiratory syndrome virus in a large population of gilts. Can J Vet Res 68, 267-273. 
Bautista EM, TW Molitor. 1997. Cell Mediated immunity to porcine reproductive and respiratory syndrome virus in swine. Viral Immunol 10, 83-94.

Benfield DA, JE Collins, SA Dee, PG Halbur, HS Joo, KM Lager, WL Mengeling, MP Murtaugh, KD Rossow, GW Stevenson, J Zimmerman. 1999. Porcine reproductive and respiratory syndrome. In: Straw BE, D'Allaire S, Mengeling WL, Taylor DJ (eds). Diseases of swine. $8^{\text {th }}$ ed. Iowa State University Press, Iowa, USA, Pp 201-232.

Bierk MD, SA Dee, KD Rossow, S Otake, JE Collins, TW Molitor. 2001. Transmission of porcine reproductive and respiratory syndrome virus from persistently infected sows to contact controls. Can J Vet Res 65, 261-266.

Cho HJ, B McNab, C Dubuc, L Jordan, A Afshar, R Magar, K Eerniss. 1997. Comparative study of serological methods for the detection of antibodies to porcine reproductive and respiratory syndrome virus. Can J Vet Res 61, 161-166.

Dee SA, TW Molitor. 1998. Elimination of porcine reproductive and respiratory syndrome virus using a test and removal process. Vet Rec 143, 474-476.

Done S, DJ Paton. 1995. Porcine reproductive and respiratory syndrome: Clinical disease, pathology, and immunosuppression. Vet Rec 136, 32-35.

Gallegos R. 2005. Estudio de la presencia de aislado nacional de PRRSV en cerdos inoculados experimentalmente en secreción nasal mediante RT-nPCR. Memoria de título, Escuela de Medicina Veterinaria, Universidad de Concepción, Concepción, Chile.

Gradil C, C Dubuc, MD Eaglesome. 1996. Porcine reproductive and respiratory syndrome; seminal transmission. Vet Rec 138, 521-522.

Holck JT, DD Polson. 2003. Financial Impact of PRRS. In: Zimmerman J, Yoon K-J (eds). PRRS Compendium. $2^{\text {nd }}$ ed. National Pork Board. Iowa, USA, Pp 51-58.

Kwang J, S Yang, FA Osorio, S Christian, JG Wheeler, KM Lager, S Low, L Chang, AR Doster, A White, CC Wu. 1999. Characterization of antibody response to porcine reproductive and respiratory syndrome virus ORF5 product following infection and evaluation of its diagnostic use in pigs. J Vet Diagn Invest 11, 391-395.

Lager KM, L Mengeling. 1995. Pathogenesis of in utero infection in porcine fetuses with porcine reproductive and respiratory syndrome virus. Can J Vet Res 59, 187-192.

López OJ, FA Osorio. 2004. Role of neutralizing antibodies in PRRSV protective immunity. Vet Immunol Immunopathol 102, 155-163.

Molitor TW, EM Bautista, CS Choi. 1997. Immunity to PRRSV: Doubleedged sword. Vet Microbiol 55, 265-276.

Osorio FA, JA Galeota, E Nelson, B Brodersen, A Doster, R Wills, F Zuckermann, WW Laegreid. 2002. Passive Transfer of Virus -Specific Antibodies Confers Protection against Reproductive Failure Induced by a Virulent Strain of Porcine Reproductive and Respiratory Syndrome Virus and Establishes Sterilizing Immunity. Virology 302, 9-20.

Otake S, SA Dee, KD Rossow, J Deen, HS Joo, TW Molitor, C Pijoan. $2002^{a}$. Transmission of porcine reproductive and respiratory syndrome virus by fomites (boots and coveralls). J Swine Health Prod 10, 59-65.

Otake S, SA Dee, KD Rossow, HS Joo, J Deen, TW Molitor, C. Pijoan. $2002^{\mathrm{b}}$. Transmission of porcine reproductive and respiratory syndrome virus by needles. Vet Rec 150, 114-115.

Otake S, SA Dee, KD Rossow, RD Moon, C Pijoan. 2002 . Mechanical transmission of porcine reproductive and respiratory syndrome virus by mosquitoes, Aedes vexans (Meigen). Can J Vet Res 66, 191-195.

Otake S, SA Dee, RD Moon, KD Rossow, C Trincado, M Farnhan, C Pijoan. 2003 ${ }^{\text {a }}$ Survival of porcine reproductive and respiratory syndrome virus in houseflies. Can J Vet Res 67, 198-203.

Otake S, SA Dee, RD Moon, KD Rossow, C Trincado, C Pijoan. 2003 ${ }^{\mathrm{b}}$ Evaluation of mosquitoes, Aedes vexans, as biological vectors of porcine reproductive and respiratory syndrome virus. Can J Vet Res 67, 265-270.
Polson D, T Holck, W Chittick. 2003. A field-based performanced comparison of the new IDEXX Herd Check PRRS 2XR ELISA whith the original Herd Check PRRS ELISA. Proceeding of the American Association of Swine Veterinarians Congress, Orlando, USA, Pp 267-272.

Reicks DL, C Muñoz-Zanzi, W Mengeling, J Christopher-Hennings, K Lager, D Polson, S Dee, K Rossow. 2006. Detection of porcine reproductive and respiratory syndrome virus in semen and serum of boars during the first six days after inoculation. J Swine Health Prod 14, 35-41.

Rossow KD, EM Bautista, SM Goyal, TW Molitor, MP Murtauth, RB Morrison, DA Benfield, JE Collins. 1994. Experimental porcine reproductive and respiratory syndrome virus infection in one-, four-, and 10-week-old pigs. $J$ Vet Diag Invest 6, 3-12.

Rossow KD, JE Collins, SM Goyal, EA Nelson, J Christopher-Hennings, DA Benfield. 1995. Pathogenesis of porcine reproductive and respiratory syndrome virus infection in gnotobiotic pigs. Vet Pathol 3, 361-373.

Rossow KD. 1998. Porcine reproductive and respiratory syndrome. Vet Pathol 35, 1-20.

Ruiz A, L Cuevas, J Naranjo. 2003. Chile: Program to erradicate PRRS virus. In: Zimmerman J, Yoon KJ (eds). PRRS Compendium. $2^{\text {nd }}$ ed. National Pork Board, Iowa, USA, Pp 221-222.

Sandoval DA. 2004. Detección del virus PRRS y anticuerpos circulantes en cerdos inoculados experimentalmente con un aislado nacional. Memoria de título, Escuela de Medicina Veterinaria, Universidad de Concepción, Concepción, Chile.

Shin J, J Torrison, CS Choi, SM Gonzalez, BG Crabo, TW Molitor. 1997. Monitoring of porcine reproductive and respiratory syndrome virus infection in boars. Vet Microbiol 55, 337-346.

Shin J, EM Bautista, YB Kong, TW Molitor. 1998. Quantitation of porcine reproductive and respiratory syndrome virus RNA in semen by single-tube reverse transcription-nested polymerase chain reaction. J Virol Meth 72, 67-69.

Spagnuolo-Weaver M, IW Walker, F McNeilly, V Calvert, D Graham, K Burns, BM Adair, GM Allan. 1998.The reverse transcription polymerase chain reaction for the diagnosis of porcine reproductive and respiratory syndrome: comparison with virus isolation and serology. Vet Microbiol 62, 207-215.

Trincado C, S Dee, L Jacobson, S Otake, K Rossow, C Pijoan. 2004. Attempts to transmit porcine reproductive and respiratory syndrome virus by aerosols under controlled field conditions. Vet Rec 154, 294-297.

Wills RW, J Zimmerman, KJ Yoon, SL Swenson, LJ Hoffman, MJ McGinley, HT Hill, KB Platt.1997. Porcine reproductive and respiratory syndrome virus: routes of excretion. Vet Microbiol 57, 69-81

Wills RW, AR Doster, FA Osorio. 2002. Transmission of porcine and reproductive and respiratory syndrome virus (PRRSV) to agematched sentinels pigs. J Swine Health Prod 10, 161-165.

Wills RW, AR Doster, JA Galeota, JH Sur, FA Osorio. 2003. Duration of infection and proportion of pigs persistently infected with Porcine Reproductive and Respiratory syndrome virus. J Clin Microbiol 4, 58-62.

Yoon KJ, HS Joo, WT Christianson, RB Morrison, GD Dial. 1993. Persistent and contact infection in nursery pigs experimentally infected with porcine reproductive and respiratory syndrome (PRRS) virus. J Swine Health Prod 1, 5-8.

Yoon KJ, J Zimmerman, SL Swenson, MJ McGinley, KA Eernisse, A Brevik, LL Rhinehart, ML Frey, HT Hill, KB Platt. 1995. Characterization of the humoral immune response to porcine reproductive and respiratory syndrome (PRRS) virus infection. $J$ Vet Diagn Invest 7, 305-312.

Yoon KJ, J Zimmerman, CC Chang, S Cancel-Tirado, KM Harmon, MJ McGinley. 1999. Effect of challenge dose and route on porcine reproductive and respiratory syndrome virus (PRRSV) infection in young swine. Vet Res 30, 629-638. 